\title{
Popular music and school music education: Chinese students' preferences and dilemmas in Shanghai, China
}

Wing-Wah Law and Wai-Chung Ho

\begin{abstract}
This empirical study investigates Chinese students' popular music preferences in daily life and to what extent and in what ways they prefer learning popular music in school in Shanghai, China. Data were drawn from questionnaires completed by 1,730 secondary students (aged 1217) and interviews with 60 students from 10 secondary schools, between September and October, 2011. Findings from these efforts were supplemented by and triangulated with data from interviews with 18 music teachers and school leaders. Findings revealed the cultural diversification and rational consumption of popular music by Chinese students in and out of school, as well as the cultural dilemmas those students confront due to their preferences for popular (Chinese and non-Chinese) and classical music in the school music curriculum. These findings can be interpreted as indicating that music and music education in formal or informal settings are complex cultural constructs that can be reinvented through the intertwined interplay of different actors concerned with the selection of music elements in a multileveled, multicultural world.
\end{abstract}

\section{Keywords}

China, cultural diversity and dilemma, popular music, music education, Shanghai

\section{Introduction}

Numerous studies have shown that many students in developed countries (such as Australia, the United Kingdom and the United States) are torn between two worlds when learning popular music: the world inside the school and that outside the school. These studies show that schools in these countries have attempted, with limited success, to bridge this gap by including popular music in the school music curriculum and improving the pedagogy of teaching popular music. Few studies, however, have examined the learning of popular music in music education programs in developing countries, such as China, which have a shorter history of popular music and are faced with the technology-assisted penetration of popular music from developed countries. This research deficit warrants attention.

With reference to Shanghai, China, this empirical work explores Chinese students' preferences for popular music in their daily and school lives. Data were drawn from over 1,700 questionnaires completed by students, and some 80 individual interviews with students, music teachers and school leaders (including principals and deputy principals) from 10 junior and senior secondary schools in Shanghai between September and October, 2011. The study reveals four major patterns of students' popular music preferences. The first two depict students' dayto-day popular music consumption patterns: diversity in selection from different cultures, and rational consumption behaviors. The other two patterns relate to students' learning of popular music in school: the divide between what students want and schools provide, and how students 
want their school to narrow that divide. These patterns further reflect students' increasing exposure to and awareness of the outside world, the continued inter-cultural dilemma between Chinese popular music and that of other countries, the intra-cultural divide between popular and classical music, and the coexistence of facilitating conditions and barriers to the promotion of popular music education in schools. This article argues that students' preferences for and dilemmas in learning popular music in and out of school results from the interplay of various actors, from the individual level to the global, shaping music and music education in a diversified, multileveled cultural world.

The article first reviews the literature on the learning of popular music in and outside school. Next, it describes the study's background, design and methodology. Third, it presents its major findings on patterns of Chinese students' preferences for popular music in daily life and for learning popular music in school. Finally, the article proposes some possible explanations for their choices, before concluding with a discussion of music and music education as cultural constructs in a multileveled, multicultural world.

\section{Divide between student learning of popular music in and outside school}

In many developed countries, students are caught in a dilemma between either learning popular music in school or in the wider society. While popular music can be difficult to define, it can be regarded as the most preferred music style, having a wide appeal with the help of mass media and technology (Shah, 2006). Popular music has long been integral to many young people's daily lives, and the media of post-World War II has intensified this trend. Although they might not aspire to be performers, young people, as Walker (2001, p. 16) observed, like listening to popular music and are 'willing to invest time and money as listeners'. Popular music is easily accessible through various media, including radio, television, Internet, and personal portable devices, such as MP3 players and smartphones; as passive media consumers, students are increasingly exposed to and become familiar with popular music through repeatedly listening or watching. According to White and McCormack (2006), American teenagers spent only slightly fewer hours listening to popular music than they spent at school over their 12-year enrollment. As in the 1950s and earlier, young people in many societies even become active consumers of popular music by joining fan clubs and promoting the popular music of their favorite artists (Fung, 2009; Shin, 2009). In some developed societies, such as Japan and Hong Kong (Ho, 2002; Koizumi, 2002), young people go with friends or classmates to private or public Karaoke places to sing popular songs.

Despite its rapid growth and increasing popularity among young people across the globe in recent decades, popular music has not been a significant part of school music curricula in many countries, including the United States (whose popular music industry is one of the largest in the world). Several studies have questioned the relevance of school music education to students' music world. One of the earliest critics was Tagg (1966), who admonished school music curricula for being divorced from students' music world, and school music teachers for ignoring popular music as a possible music teaching resource. Students' music learning, as Mills (2000) and Stuessy (1994) observed, is dichotomized into two musical worlds: the 'world of classroom music', which focuses on folk songs, choral anthems and concert band overtures, and the 'world of music outside the classroom', which centers on popular music. As Green (2006, p. 101) vividly pointed out, students often see school music as 'old people's music' and popular music as their own. Students are enculturated into popular music by the acquisition of musical knowledge and skills through their 'immersion in the everyday music and musical practices of [their] social context' (Green, 2002, p. 22) in an informal musical education environment, prolonged and extensive exposure to popular music and information about it via the Internet, radio and television, and popular music concerts and festivals (Snell, 2005). 
Students learn more about popular music in these informal music education environments than they do in schools and universities.

Many efforts have been made to narrow the divide between students' in and out of school musical worlds by including popular music in formal music curricula. A representative effort in the United States was the 1967 Tanglewood Declaration, which advocated an accommodation approach of incorporating '[m]usic of all periods, styles, forms, and cultures' into the American curriculum and expanding the musical repertory to include jazz, folk, pop, avant-garde, and music from other cultures (Mark \& Madura, 2010, p. 120). In a similar vein, music education experts in Britain, such as Swanwick (1968) and Vulliamy and Lee (1980), strongly advocated for the inclusion of popular music in the British school curriculum. By the 1970s, the United States, United Kingdom and Australia had all gradually begun to incorporate popular music in their school music curricula (Dunbar-Hall, 2002; Dunbar-Hall \& Wemyss, 2000; Hebert \& Campbell, 2000; Walker, 2001). The movement towards incorporating popular music as a study topic later spread to Japan (Koizumi, 2002), as well as to some developing countries, such as Malaysia (Shah, 2006). Since then, research into popular music and popular music education (e.g., Dunbar-Hall \& Wemyss, 2000; Green, 2001, 2006; Winter, 2004) has begun to take shape.

Despite these efforts, popular music has still not been 'fully embraced as a genre worthy of meaningful study', and the weight of popular music in school music curricula remains minimal, both in the United States and elsewhere (Thompson, 2007, p. 36). In Japan, students still conceal their personal musical tastes when in school and draw a distinction between the popular music present in their daily lives ('everyday knowledge') and the music they encounter in school ('school knowledge') (Koizumi, 2002, p. 107).

As shown in a number of studies, the promotion of popular music in school confronts two major types of barriers: perceptual and practical. The first category is related to adults' stereotypical perceptions of popular music, and includes: concerns about popular music's perceived links to social and teenage problems (e.g., rebellion, drug use and sexual activity) (Green, 2006; Seifried, 2006) and its resultant negative impact on young people's thoughts, behaviors and feelings (Brown, 2006); stereotypical views that classical music is the music of the educated, cultured elite, while popular music is the music of the unwashed masses; and the belief that popular music is merely entertainment, while traditional or classical music is an object of cultural heritage and teaching it is a means of cultural preservation. Practical barriers include: the low priority afforded music in the larger school curriculum; music teachers' insufficient knowledge of and skills in popular music, and their lack of training and confidence in teaching it to students who are more knowledgeable of and 'educated' in popular music than they (Woody, 2007); the rapid pace of change in popular music trends and technology; and low availability of popular music instruments (such as electronic keyboards, guitars, drum machines) and electronic technology to allow students to compose rather than depend on notational literacy (Dunbar-Hall \& Wemyss, 2000).

\section{Popular music and music education in Shanghai}

As in many other societies, popular music in Shanghai and other areas of China is strongly welcomed by young Chinese people but is very minimally present in the school music curriculum. In 2009, Shanghai had a population of 19.2 million (Shanghai Municipal Statistical Bureau, 2010). Its per-capita gross domestic product (GDP) was US $\$ 11,451$, higher than China's (US\$4,400). There were roughly 671,000 students in Shanghai's 751 primary schools, and 604,000 students in its 762 junior secondary (grades 7-9, with students aged 12-14), senior secondary (grades 10-12, with students aged 15-17) and combined junior/senior secondary schools. As elsewhere in China, Putonghua is the common oral language used in schools and 
on public occasions in Shanghai; although Shanghai has its own dialect, many Shanghai children have limited proficiency in Shanghaiese.

Shanghai has a longer history of exposure to Western music and cultures than do other cities in China. In the early 1840s, foreign powers forced the Chinese government to open the port of Shanghai to foreign traders. As a result, pre-1949 Shanghai became one of China's most Westernized cities (Hayhoe, 1988), open to and accepting of the cultures and lifestyles of Western countries, particularly that of the United States; American popular music, including jazz, was quite popular in Shanghai's nightlife (Chen, 2005); parallel to the penetration of Western music, however, was the emergence and popularization of Chinese popular music. The 1920s and 1930s witnessed the golden age of Shanghai's popular music and the birth of the modern Chinese popular music industry (Chen, 2005). With the Communist Party of China's (CPC's) rise to power in 1949, however, the dissemination of Western music and cultures was banned across China for ideological reasons.

In 1978, China reversed its largely isolationist foreign policy, expanding its existing foreign ties, once limited to mainly communist countries, to include capitalist countries. As a result, Shanghai was once again exposed to Western culture and music, including rock, pop and reggae; from the late 1980s to the mid-1990s, as Farrer (2000) observed, Shanghai and other large Chinese cities were swept up in a Western disco dance and music craze. The policy of opening China to the world has also enabled the promotion, among Shanghai's young people, of popular music from other Asian societies, including Taiwan, Japan and South Korea. At the same time, however, China's domestic popular music industry has grown dramatically, and Shanghai's young people have increasingly been enculturated - via radio, television and the Internet - to accept Chinese popular music more than Western.

As in other countries and elsewhere in China, Shanghai provides school students with formal music education. Music learning is offered as an independent subject in primary and junior-secondary school curricula, and as an essential component of the integrated subject, Arts, in the senior-secondary curriculum. Since China's curriculum reforms of the 1990s, Shanghai's school music curriculum has aimed to cultivate students' musical sensitivity and love of music, develop their aesthetic judgment, and promote Chinese national music and foreign compositions (Shanghai Municipal Education Commission, 2004).

In its nationwide curriculum reforms, China emphasized exposing students to a diversity of music from different societies and the importance of relating music learning to students' daily lives (2001), but did not give popular music official status in the revised national school music curriculum (Ho, 2010). Despite this, in the mid-2000s, the Shanghai Municipal Education Commission (2004, p. 42) encouraged schools to help students understand music of 'different cultural backgrounds' and from 'different periods' in and outside of China, to some extent reflecting the spirit of the 1967 Tanglewood Declaration. Shanghai music textbooks began to include popular songs, and music from popular films and stage productions, both Chinese and from other cultures. Music teaching resources included Taiwanese popular songs (such as Snail by Jay Chou), songs from Cats, Phantom of the Opera and other popular Western musicals (Shanghai Juvenile and Children's Publishing House, 2004, 2009), and theme music from popular Chinese and Western movies, such as Crouching Tiger, Hidden Dragon, Star Wars and Titanic (Shanghai Juvenile and Children's Publishing House, 2011; Shanghai Music Publisher, 2005). Despite such recent inclusions, however, the weight of popular music in the Shanghai's school music curriculum remains, as shown later in this study, far less than what Chinese students want, and the gap between learning popular music in and out of the classroom is still huge.

The extant literature on popular music and popular music education can shed some light on Chinese students' preferences for popular music and how their learning of popular music is divided between experiences in and outside of the classroom. However, it is under-researched 
in regards to whether students in Shanghai are, like their counterparts in developed countries, caught in a dilemma between learning popular music in school or in the wider society. Specifically, it cannot explain two major aspects of Shanghai's case: the ways and extent to which students prefer to have popular music in their daily lives and school curriculum; and, the diverse selections of popular music from different cultures and cultural dilemmas confronting students in both formal and informal musical education environments. This empirical study addresses both aspects.

\section{The research study}

With specific reference to Shanghai, the study explores students' preferences for popular music in and outside of school. It addresses four specific research questions: (1) To what extent do Chinese secondary students (aged 12-17) enjoy popular music in their daily lives? (2) What are their preferences for learning popular music in and outside of school music lessons? (3) Why informs these preferences? (4) What are the facilitating conditions for and challenges to promoting popular music in schools?

In this small-scale study, we selected 10 Shanghai secondary schools - five juniorsecondary schools and five senior-secondary schools. Because, in Shanghai as in elsewhere in China, it is difficult for outsiders to gain access to schools for research purposes, these schools were accessed mainly through local academics. The schools were all located in urban areas, and were ordinary schools whose students were average academic performers. According to students and staff in interviews, many of the students in these schools engaged in extracurricular activities in sports, music and other arts. In addition to document analysis, the study used two major research methods to collect data: a questionnaire survey and interviews.

We administered an anonymous questionnaire to solicit the views of a large sample of student informants in an economical and efficient manner (Cohen, Manion, \& Morrison, 2007). We drafted the questionnaire in simplified Chinese, which was the native language of the subject students. To ensure its wording and terms were clearly understood by student respondents, we administered a pilot questionnaire to five junior secondary and five senior secondary Shanghai students enrolled in other, non-subject schools. Based on responses to the pilot, we slightly modified some questionnaire items, such as using oral languages to differentiate popular songs from mainland China (Putonghua), Taiwan (Mandarin) and Hong Kong (Cantonese). The final questionnaire comprised three major sections. The first collected basic information about students' gender, age, grade level, major sources of music knowledge and musical instrument training. The second section asked students to what extent and why they liked popular music from different societies, who their popular music idols were, and what their popular music listening, watching and singing habits were. The third section explored students' preferences regarding the promotion of popular music in their school. In particular, it asked how often they learned, and how interested they were in learning, popular music from different societies in school music lessons, whether their school should promote popular music, and how their school could help them to learn popular music. Most questions adopted a fourpoint Likert scale to allow respondents to express degrees of either agreement, approval, importance or frequency; for example, 1 represents strongly disagree, 2 disagree, 3 agree, and 4 strongly agree. The question items were found to have very high reliability, with a Cronbach's alpha of 0.99 .

In September, 2011, we asked the principals of the 10 subject schools for permission to collect data from their students. The principals arranged to have their teachers distribute 1,900 questionnaires to students for completion in class; 1,850 completed copies were returned, for a return rate of $97.4 \%$. The average time for completing the questionnaire was about 20 minutes. Of the returned questionnaires, 1,739 (94\%) were usable, including 763 from students in five junior-secondary schools (grades 7-9), and 976 students in five senior-secondary schools 
(grades 10-12) (Table 1). Of the respondent students, 53.9\% were male and $46.1 \%$ were female. Regarding the distribution among grades, fewer students were from grades 9 and 12 than from other grades. This is understandable, as students in these grades were preparing for public examinations at the time of the questionnaire, and the subject schools were therefore less willing to have them participate.

\section{[Table 1 about here]}

In addition to the questionnaires, semi-structured interviews were conducted to probe into and clarify interviewees' perceptions, views and interpretations (Merriam, 1998; Patton, 1990). The interviewees included: 60 students in grades 7-12 who were consumers of music education; nine music teachers who were responsible for teaching music education and organizing music activities; and two principals and seven deputy principals who set school policy and allocated resources for music education (see Table 1 for more information). The subject schools selected the students to be interviewed. In their interviews, the students were asked to respond to three broad questions: (1) whether they liked popular music and why; (2) whether they preferred learning popular music through school music lessons and why; and, (3) whether their teachers had or would have difficulty teaching popular music. School leaders and music teachers were asked four broad questions in their interviews: (1) whether they wanted to incorporate popular music into their school music curriculum; (2) what challenges or difficulties they had faced in promoting popular music in their school; (3) what efforts could be made to address these challenges or difficulties; and, (4) whether the teaching of popular music could challenge the status of classical music in the music curriculum. All interviews were conducted on an individual basis in Putonghua (China's common oral language) and were audio-recorded with the permission of the interviewees. The average lengths of the student and staff interviews were about 20 and 30 minutes, respectively.

This study used Statistical Package for Social Sciences (SPSS) software to analyze the questionnaire data, identify patterns in students' responses, and explore interrelationships. Content analysis was used to examine interview data by post-coding interviewees' responses and looking for patterns in their words, phrases, and thoughts that related to the research questions and to the patterns identified from the questionnaire data (Wiersma \& Jurs, 2004). Due to the difficulty in gaining access to schools, this study has some limitations, including its small scale and the non-representativeness of subject schools and respondents. The researchers have no intention, however, to generalize the study's findings to students and staff in other schools in and outside of Shanghai.

\section{Major questionnaire findings}

This section reports the major findings of the student questionnaire survey. The surveyed students' background information shows that peers, rather than music teachers, were the most important source of their music knowledge. Students' top five music knowledge sources were: friends $(81.9 \%$, i.e., 1,425 of 1,739 students); classmates $(80.9 \%)$; electronic media including Internet, radio, and television (77.8\%); popular music idols (77.0\%); and school music teachers (72.2\%). In the 12 months before the survey, about $910(52.3 \%)$ of surveyed students had visited karaoke establishments three to six times. The study revealed four major, interrelated patterns regarding Chinese students' preferences for popular music in their daily lives and school music education; T-test and ANOVA indicated that these patterns did not differ significantly between junior and senior secondary students. Senior secondary students rated ratings only a few of the 89 questionnaire items (spread over different questions) significantly higher than their junior counterparts, and vice versa; thus, this study offers no conclusive empirical evidence of a strong correlation between educational level and students' preferences 
for popular music in and outside of school. It does, however, find significant correlation between gender and students' preferences; this deserves to be the subject of another paper, as it requires a separate review and discussion of the issues of gender and popular music. (The next section will use interview data to elaborate and explain these survey findings.)

\section{Consumption patterns of popular music in students' daily lives}

The first pattern in students' preferences is related to the diversity of popular music in Chinese students' daily lives. The survey shows that a majority of the 1,739 surveyed Chinese students liked popular music, their favorite type being that of their homeland, mainland China, in Putonghua (88.4\%) (Figure 1). They also indicated that they liked popular music from other Western and Asian countries, to various extents; they liked popular songs from the UK and the US (81.6\%) more than Chinese popular songs from Taiwan (62.0\%), Asian popular songs from Japan (68.3\%) and South Korea (56.2\%), and popular songs from other Western countries $(56.8 \%)$. As shown in Figure 1, surveyed Chinese students who had visited karaoke places in the preceding 12 months expressed almost the same pattern of diverse popular music preferences.

\section{[Figure 1 about here]}

The second pattern is concerned with students' behaviors in consuming popular music. The survey shows Chinese students to be 'rational' consumers, rather than blind followers, of popular music. First, students cared more about the overall quality of the music than the popularity of the performing artists; $95.6 \%$ liked popular music primarily because of its melody, $86.4 \%$ liked it for its lyrics and $85.7 \%$ for its power to arouse sympathetic responses, compared to only $66.6 \%$ who liked it because of the artist. Second, the artist's quality is more important than their promotion and packaging. Although 1,240 (71.5\%) of surveyed students had their own popular music idols, their ratings suggest that this approval was based on the artists' melodies and lyrics (97.1\%), performance styles and skills (88.4\%) and achievements $(72.3 \%)$, rather than their physical appearance $(66.5 \%)$, modern outlook $(57.1 \%)$, media attention $(53.4 \%)$ or the recommendations of their friends or classmates $(50.6 \%)$. Third, a majority of the 1,739 surveyed students listened to or watched popular music mainly outside of their study time. The survey shows that students spent between six and 15 hours per week, on average, listening popular music, either after completing their homework (66.7\%), during recess $(45.1 \%)$, and/or on their way to or from school $(35.8 \%)$; only $25.1 \%$ of student respondents indicated that they listened to popular music while doing homework. Students preferred listening to or watching popular music on the Internet $(87.1 \%)$ and iPods or MP3 players $(86.9 \%)$ more than on television $(61.7 \%)$, radio $(58.1 \%)$, mobile phones $(49.6 \%)$ or $\mathrm{CD}$ players $(45.8 \%)$.

\section{Students' preferences for learning popular music in school}

The third pattern of students' preferences for popular music is related to the diversity of China's school music curriculum. The surveyed Chinese students preferred having a more open and culturally diversified music curriculum that included more popular music and music from other cultures than the existing curriculum; in other words, they wanted the school music curriculum to reflect more closely their day-to-day music preferences, over which they had more control. Overall, they saw their school music curriculum as favoring Chinese music over non-Chinese music, and traditional music over contemporary music (Figure 2). Of the 22 musical styles listed on the questionnaire, $46.3 \%$ of students said that their school music education emphasized Chinese folk songs; $33.5 \%$ said traditional Chinese orchestral music; $29.7 \%$ 
traditional Western orchestral music; $26.0 \%$ modern Western opera; 25.5\% popular songs from mainland China; and, $24.0 \%$ traditional Western opera.

[Figure 2 about here]

When asked, however, which of the 22 musical styles presented they would most prefer to learn in school music lessons, however, only $31.9 \%$ chose Chinese folk songs, while just $26.9 \%$ felt traditional Chinese orchestral music should be emphasized. Rather, the majority of students wanted to increase the importance of other musical styles from diverse societies, particularly popular songs from mainland China (70.9\%), the UK and the US (67.2\%), Japan (59.1\%), Taiwan (55.3\%) and South Korea (53\%), similar to the students' day-to-day popular music preferences. In addition, most students also supported greatly increasing the attention paid to other Western musical genres, including rap and hip-hop (54.3\%), blues and jazz $(52.2 \%)$, rock $(50.1 \%)$ and punk $(46.3 \%)$. Finally, students also wanted, to a lesser extent, more traditional music in local dialects in their music lessons, including Beijing opera, Shanghai opera, Cantonese opera and Kun opera.

[Figure 3 about here]

The surveyed students also expressed a preference for more exposure to popular music in the school's non-music subjects (Figure 3), including English Language (28.9\%), Chinese Language (25.4\%), Social Studies or political subjects (22.8\%), Culture and Art (20.2\%) and Math/Science (19.7\%).

The surveyed students' reasons for wanting more popular music in school can be grouped into three broad categories (Figure 4). The first concerns their intrinsic motivations for learning popular music. Students wanted more knowledge about popular music $(88.2 \%)$, to sing their favorite popular songs $(85.0 \%)$, to know more about $(81.5 \%)$ and sing as well as (76.7\%) their favorite singers, to feel that popular music was closely related to their daily lives (76.9\%), to believe that they had ability to learn popular music well $(73.1 \%)$, and to develop their careers in the popular music industry (56.5\%). Despite ranking last in this category, the popular music industry as career was still attractive to over half of all surveyed students. The second category reflects external motivations for popular music promotion; surveyed students' preferences were influenced by their classmates or friends $(74.8 \%)$, or encouraged by their school music teachers $(72.5 \%)$, parents $(69.8 \%)$ or instrumental teachers $(68.9 \%)$. Third, the surveyed students wanted to learn music $(87.7 \%)$ and practice their singing skills $(82.6 \%)$ using popular music; most (56.3\%) disliked classical/traditional music.

[Figure 4 about here]

The fourth pattern of students' preferences for popular music is concerned with how they wanted their school to provide them with more opportunities and ways to learn more popular music, in both the formal music curriculum and extracurricular activities (Figure 5). Most surveyed students $(90.5 \%)$ hoped that, in music lessons, their school would add more popular music elements, including teaching popular music $(87.0 \%)$ and songs by popular singers $(81.3 \%)$. Specifically, they indicated that the learning of popular music could be injected into various music learning activities, including singing (89.9\%), performing $(74.8 \%)$, listening $(71.6 \%)$, reading scores $(71.5 \%)$, songwriting $(69.8 \%)$, and learning to play music instruments $(66.4 \%)$. They also indicated their interest in learning the popular music histories of China (75.4\%), Western countries (74.2\%) and other Asian countries (69.8\%).

[Figure 5 about here] 
Moreover, the surveyed students indicated that their schools could increase their out of class exposure to popular music by broadcasting popular music during lunch breaks $(86.9 \%)$ and providing more information about popular music $(83.9 \%)$, and could improve their knowledge of and skills in popular music through extracurricular activities such as workshops on composing popular song lyrics $(81.7 \%)$ and music $(77.5 \%)$, performance skills $(78.4 \%)$, electronic musical instruments (80.2\%), and electronic popular music $(79.0 \%)$. The students also hoped that their school would provide them with opportunities to learn through direct communication with popular music artists, by inviting them to speak $(82.1 \%)$ or even perform (77.3\%) at the school. It should be noted that, despite their strong preference for learning popular music, most surveyed Chinese students recognized the importance of striking a balance between learning popular and traditional music, both Chinese $(80.3 \%)$ and Western $(77.3 \%)$.

\section{Possible explanations for the study's findings}

This section considers some possible explanations for the surveyed students' diversity in choice of musical styles and the divide between learning popular music in and outside of school. These include Chinese students' increasing exposure to musical styles from different cultures in a global age; continuing cultural learning dilemmas between classical and popular music, and between Chinese and Western music; and, the coexistence of facilitating conditions for and challenges to the provision of popular music education in school. The following discussion is grounded mainly on document analysis and interview data.

\section{Increasing exposure to popular music of different cultures in a global age}

In their day-to-day lives and while engaged in Karaoke entertainment, the student respondents showed a clear preference for diverse popular music from different societies, claiming to either 'like' or 'strongly like' popular music from China, Western countries and other Asian societies. This diversity can be partly explained as a result of Chinese students' increasing exposure to different cultures within and outside of China through various media, including radio, television, the Internet, and other electronic devices in a global age. There are three major, related reasons for such an increase.

First, at the policy level, since the late 1970s, China's foreign policy has changed from one of limited self-containment to one of opening the country to the world, thus providing Chinese people (including students) with more opportunities to know and interact with other peoples in an increasingly globalized world. This policy change has also enabled a greater inflow of non-Chinese popular cultural elements from around the world (Landsbeger, 2009) and increased the penetration of foreign music and artists into the Chinese music market.

Second, since the 1980s, China's TVs and music entertainment businesses have helped to promote, not only Chinese popular music, but also popular music from other Asian societies and the West. In particular, the broadcast of TV dramas from Japan, South Korea and Taiwan has indirectly promoted those countries' popular music within China; the 2000s, for example, saw a widespread 'Korean wave', an influx of Korean dramas and popular music, in China (Pease, 2006).

Third, the Internet and Internet-connected mobile phones have become a convenient means by which Chinese students can access popular music from within and outside of China. As of December, 2011, China had 513 million netizens (about $40 \%$ of its population or 1.5 times the population of the United States) and 356 million people with Internet-connected mobile phones (China Internet Network Information Center, 2012). In 2010, students accounted for $30.2 \%$ of China's netizen population; at the same time, the third most popular use of the Internet (used by $75.2 \%$ of Chinese netizens) was for Internet music, while Internet video use (used by 63.4\%) ranked fifth. In interviews, many students explained that the Internet 
had helped them diversify their sources of popular music by allowing them to listen to and watch videos of 'popular songs by singers based both in and outside of China', and to 'download their music for later replay'. Some students (such as SchA-S4, SchD-S4, SchG-S3, and SchI-S6) listed 'singers whose songs were [first] made popular on the Internet' (wangluo geshou) as one of their favorite popular artists. All this suggests that, due to China's Open Door policy, the breadth and depth of Chinese students' day-to-day exposure to other cultures through various modes of media has grown, influencing their musical behaviors and popular music choices.

\section{Continued dilemmas of students' musical preferences in a multileveled cultural world}

Despite their preference for popular music with diverse origins in a multileveled cultural world, the student respondents faced two major, ongoing music learning dilemmas - an intercultural divide between Chinese and Western popular music, an intra-cultural divide between popular and classical music.

The first relates to the inter-cultural nature of the global music world. Findings from the questionnaire survey indicated that Chinese students liked Chinese and Anglo-American popular music to similar extents in their daily lives and as Karaoke entertainment, and preferred learning both if they were allowed to choose the content of school music lessons. Interview findings reveal a spectrum of reasons for students' preferences. The two commonly cited general reasons were that both types of popular music had 'unique characteristics' (SchA-S3 and SchB-S5), and both were 'pleasing to listen to', regardless of their language (SchD-S2 and SchG-S5). Some students loved Chinese popular music because songs in Chinese helped them to 'feel the singer's emotions' and 'express their own emotion better' (SchA-S4, SchB-S4, and SchE-S4), while others liked being 'able to understand the Chinese lyrics' (SchF-S4 and SchIS1). Students preferred English popular songs because their melodies and rhythms were 'more to their taste' (SchC-S3 and SchJ-S2); listening to and singing English-language popular songs could help them 'improve their English proficiency' (SchC-S1 and SchH-S3); and, compared to other foreign languages (such as Japanese and Korean), it was "easier to understand English lyrics", because the students had studied English since primary school (SchH-S3).

The second dilemma has been a longstanding one between popular music and classical music, produced in different periods within the same culture. The surveyed students, as shown above, preferred learning popular music to learning classical music in school, regardless of whether it were Chinese or Western in origin, for a variety of reasons. This does not mean, however, that they totally rejected learning classical music in school; in their interviews, many students indicated that they just wanted 'to reduce the weight' of the traditional Chinese music component, 'not remove it' from the school music curriculum altogether. The two most cited reasons for wanting to learn classical music in school were that: (1) unlike popular music, students had 'fewer opportunities' to listen to and learn classical music outside of school; and (2) learning classical music could help them learn music in a 'more well-rounded manner'. In other words, although many respondents wanted to learn more popular music in school, they nonetheless wanted classical music to remain a part of the school music curriculum.

\section{Facilitating conditions for and challenges to the promotion of popular music in school}

Interview findings reveal two major facilitating conditions for promoting popular music in Shanghai's secondary schools. First, students were very eager to learn it; in general, the interviewed students indicated that they were strongly motivated to learn popular music for a variety of reasons (presented earlier) and urged the schools to help them do so through various formal and informal school curriculum activities.

Second, a majority of interviewed music teachers and school leaders (including principals and deputy principals) recognized and accepted popular music as valid topic of study 
in the music curriculum, and all of them considered popular songs to be both music and art. However, there is a debate between interviewed staff as to whether popular music should be taught. Two interviewed music teachers (SchA-T3 and SchA-T4) opposed teaching popular music because they considered it 'not good enough to be learned', while the remaining 16 interviewed staff felt that popular music should be 'officially recognized and included' in Shanghai's school curriculum. Commonly cited reasons for its inclusion included 'to motivate students to learn music'; 'for music appreciation and music analyses' purposes; to ensure a 'well-rounded education'; and, 'to ensure teenagers do not blindly follow their popular music idols'. For different purposes and to different extents, all 10 subject schools included popular music in their music lessons. Moreover, except for two deputy principals (SchC-T1 and SchGT1), none of the interviewed music teachers or school leaders considered the teaching of popular music a threat to the status of classical music in the school music curriculum, as both types of music have their own 'musical features' (yinyue tese) and 'power of attraction' (meili).

Despite students' willingness to learn it and frontline school practitioners' willingness to teach it, the interview findings reveal that promoting and providing popular music in Shanghai's school curriculum faced three major challenges. The first is related to content selection. About two-thirds of the 18 interviewed staff admitted that making appropriate music selections could be challenging because of music teachers' 'lack of professional training' in popular music education (e.g., SchF-T2 and SchG-T2) and 'lack of teaching and learning resources' (SchG-T3). Interviewed students expressed additional concerns about popular music lessons, including the existence of a 'generation gap' between music teachers and students in terms of their popular music 'interests' and 'choices' (e.g., SchA-S3, SchB-S2, SchG-S6, and SchH-S2), 'the difficulty of satisfying the diverse popular music preferences' of a large student body (SchG-S4, SchJ-S3, and SchJ-S6), and 'the challenge of keeping abreast of changes in both popular music and students' musical tastes' (SchD-S5). As one student (SchC-S2) commented, his 'music teacher does not know what popular music students like'.

The second challenge, which is related to the first, concerns music teachers' ability to teach popular music. As mentioned above, Shanghai's music teachers lack professional training in popular music. In separate interviews, one school principal (SchI-T1) and three deputy principals (SchA-T2, SchC-T1, and SchG-T1) all insisted that, before popular music could be taught, music teachers would 'need to receive professional training' to enhance their basic knowledge about and skills in teaching popular music; this was echoed by all nine interviewed music teachers and several interviewed students (e.g., SchG-S5). Music teacher training institutes, some interviewed school leaders suggested, could offer 'thematic workshops on popular music' (SchF-T1) and 'develop criteria for selecting materials for teaching popular music' (SchH-T1). Some interviewed music teachers (such as SchG-T3) hoped, more pragmatically, that music-teacher training institutes would 'help them to develop teaching and learning resource banks'.

The third and more important challenge concerns the marginalization of music education in the larger school curriculum. Despite acknowledging the benefits of teaching popular music in schools, many interviewed music teachers and school leaders indicated that music education was of low overall importance to schools in general because of Chinese education's 'examination-oriented culture' (SchA-T4, SchF-T1) and the subject's 'low priority in education policy' (SchF-T2). The principal of School I (SchI-T1) went so far as to say that it was 'difficult to guarantee teaching time for music lessons' at his school. Due to the low overall status of music education, popular music, one interviewed music teacher (SchJ-T1) admitted, has 'no status at all' in Shanghai's school music curriculum. Students shared staff's pessimism about teaching popular music in schools; many interviewed students (such as SchAS2, SchB-S4, SchG-S4, and SchH-S6) said that, while their music teachers did not oppose their learning popular music, they cautioned them 'not to spend much time' on it and, more 
important, 'not to let it affect (their) academic study' and 'performance on the public examination'.

Some interviewed school leaders and music teachers (e.g., SchA-T2 and SchH-T2) noted that it is national and local education authorities, not the individual schools, who will decide whether and to what extent popular music will be included in the secondary school music curriculum. It will be difficult to promote popular music education among students unless the government 'officially recognizes the value and status of popular music in the school curriculum' (music teacher SchG-T3), and 'includes popular music in curriculum planning and provides sufficient funding to promote it' (SchA-T2, a deputy principal).

\section{Discussion: music and music education as cultural constructs in a multileveled cultural world}

The patterns of students' preferences for popular music in their daily lives and in school suggest that music and music education are cultural constructs rooted in a multileveled cultural world (ranging from the personal level to national/local and global levels). Music and music education can be continually reinvented through intertwined interactions among different stakeholders, who select different music elements from the multileveled cultural world in response to their own needs and contexts. This complex interplay can result in music learners being exposed, to varying degrees, to a wide variety of musical styles.

Although it is recognized for its universality, music can be still culturally-based and language-bounded. In a given society, music can embed and reflect its people's lifestyle, cultural values and social norms (Walker, 2001), and can help to preserve their cultural heritage and foster their cultural identity (Shah, 2006). Music, as Green (2006, p. 103) has argued, is not simply a train of 'sounds and silences'; rather, it has its own 'delineated meaning', and conveys 'social, cultural, religious, political or other such associations'. In a similar vein, popular music is socio-culturally based and constructed. In a specific society or culture, societal likes and dislikes, needs, desires, gratifications, and frustrations can refract into and be reflected by the popular music of a particular time (Meizel, 2006; Shah, 2006). The delineation of music, including popular music, however, requires music consumers and learners to understand and interpret both its contents and the contexts in which it is produced. As shown in this study, language proficiency can be a key to such understanding and interpretation, and can, in turn, affect the consumer's selection of popular music from different cultures. A majority of surveyed Chinese students, as explained in the preceding section, liked both Chinese and English popular songs, likely because Chinese is their mother tongue and they had studied English since their primary education. Comparatively few surveyed students liked popular songs from Japan, South Korea, and other Western countries, because they needed to 'expend more effort' to understand their lyrics (SchH-S3).

At the individual level, students are not necessarily passive consumers, absorbing the influences of school and the music market; rather, they can be active selectors and rational consumers of music from their multileveled cultural world. For different reasons and to different extents, they choose, like and have a sense of affiliation and identification with popular music and popular artists from various societies. In this empirical study, both the questionnaire and interview surveys have revealed the diversity of Chinese students' preferences for popular music, in terms of its origins within and outside of China, their diverse preferences for popular and classical music from different time periods, and how students' language proficiency can affect their choices of popular music from different cultures. When asked to who were their favorite popular music idols, the surveyed students named, in addition to popular Chinese artists, named a variety of popular artists from outside China: Lady Gaga (whom Chinese students cited most often), Babyface, Green Day, Michael Jackson, and Britney Spears from the United States; Justin Bieber and Avril Lavigne from Canada; Ayumi 
Hamasaki, Kuraki Mai and the female idol group AKB48 from Japan; and M2U and the male idol group Big Bang from South Korea. Students are not blind consumers of popular songs in the globalizing music market. Instead, as shown in this study, a majority of surveyed Chinese students were quite disciplined and spent time consuming popular music, mainly in their nonstudy time. They placed greater value on quality in popular music and popular artists than on superficial packaging, such as artists' persona or style of dress.

Students do not develop their tastes in isolation, however. Rather, they are exposed to their immediate and wider contexts and can therefore be affected by other actors. In particular, four main types of actors can shape their selection of and identification with popular music and favorite popular artists: school; the music industry and mass media; peers and classmates; and, the government.

First, schools and teachers are important agents for socializing students into different types of music. Much like their counterparts in developed countries such as the UK and the US before the 1970s, the 10 subject schools in Shanghai, as this study has shown, focused more on preserving classical music as a cultural heritage than on promoting popular music, and thus perpetuated the division of students' popular music learning into two worlds. They did, however, make some efforts to reduce the classical/traditional music imbalance in music lessons; surveyed students indicated that they had opportunities to learn both classical and popular music, even though they wanted to learn more of the latter (Figures 2 and 3). Interviewed school leaders and music teachers indicated their support for teaching popular music, but Chinese teachers are caught in a dilemma. On the one hand, they could promote learning popular music; over $70 \%$ of surveyed students confirmed that their school music teachers encouraged them to learn popular music (Figure 4). On the other hand, they could discourage students from spending too much time learning popular music out of concern that their examination performance might be negatively affected.

Second, unlike schools, which teach young people far more classical than popular music, the music industry and the mass media, which are significant shapers of people's musical tastes and choices, actively promote and disseminate popular music in global and national/local markets, while largely ignoring classical music. Young people can access and learn about popular music through various media and/or informal musical education environments (Green, 2002; Shah, 2006). Despite tight controls over access to online information authorities deem threatening to China's political leadership and social stability (Law, 2011), electronic media (including Internet, radio and TV), as reported earlier, were the third greatest source of the surveyed students' musical knowledge; moreover, the Internet and portable personal electronic devices were their favored means of listening to popular music and watching music videos. This easy accessibility to popular music can also increase students' exposure to other music styles.

Third, peers can influence and reinforce young people's musical preferences, attitudes and behaviors. Young people commonly learn from and copy one another in a number of areas, ranging from the clothes they wear to the music they listen to. As students approach adolescence, peers can increasingly affect their musical preferences (Hallam, Rogers, \& Creech, 2008). Musical tastes and behaviors can significant factors affecting young people when forming their peer circles and developing their social or group identity. With the ubiquity of technology and rise of social networking sites, popular music has become a more commonly shared cultural element among young people, especially when compared to classical music. As shown in this study, Chinese students are not immune to the influence of peers on their musical selections and knowledge. The study's findings indicated that peers and friends were surveyed Chinese students' two main sources of music knowledge; about three-quarters of surveyed students even indicated that their friends and classmates had influenced them to learn popular music (Figure 4). Similar to their counterparts in Japan and Hong Kong, over half of the 
surveyed Shanghai students went to Karaoke places with their peers from three to six times in the 12 months before the survey.

Fourth, the government, as a major curriculum setter and resource allocator, can play a vital role in deciding what students can and should learn in school music curricula, and in balancing students' learning of different musical styles and music from different cultures. Although the 2001 national music curriculum did not explicitly encourage it (Ministry of Education, 2001), the 10 subject schools in Shanghai nonetheless included popular music (though to a very small extent) in their school music classes; in part, this was due the Shanghai government's endorsement of students' need to learn music from a variety of times and cultural backgrounds. Making the national music curriculum more amenable to popular music, as suggested by the interviewed music teachers and school leaders, requires more openness on the part of the national government when formulating China's musical education policy and curriculum. In December, 2011, China's Ministry of Education (2011) promulgated the revised music curriculum for primary and junior-secondary education; it officially endorses, for the first time, teaching popular songs to students in grades 3-6.

Just how open China's music education policy makers are to the teaching of popular music remains to be seen. Respondent students and staff who supported popular music learning in school might be disappointed by the revised national music curriculum, which stipulates that the popular songs taught must be 'healthy' (jiankang), but has not specified their selection criteria (Ministry of Education, 2011, p. 16). Moreover, although China has operated under an Open Door Policy since 1978, its government remains, as then President Hu Jintao (2012) admitted, very mindful of the historical impact of cultural imperialism by foreign countries. It has emphasized the need to cleanse China's social and cultural environments to ensure young people's 'healthy growth' (jiankang chengzhang), by preventing the spread harmful, pornographic or vulgar information (Communist Party of China Central Committee \& State Council, 2012). We expect that the Chinese state is likely to continue to exercise tight control over both domestic cultural products and foreign cultural imports, and local education authorities and schools are likely to select 'healthy' popular songs teach. China's case suggests that government can be a principal selector of and gatekeeper for cultural elements and forms (including music) from both within and outside of its borders in a diversified, multileveled cultural world.

\section{Conclusion}

With reference to Shanghai, this article has explored in what ways and to what extent Chinese students prefer to consume popular music in their daily lives and at school. Although most of the surveyed students liked both to enjoy popular music in their daily lives and to learn popular music in school, this empirical study finds a significant divide in Shanghai between students' learning of popular music in and outside of school, similar to that found by other studies in developed countries (e.g., Green, 2006; Jaffurs, 2006; Mills, 2000). The popular music world of many Shanghai students, however, is more culturally diverse than that of the subjects in other studies. The Shanghai students liked Chinese (Putonghua) and English popular music, as well as popular music from China's Asian neighbors, including Japan and South Korea. They also preferred a more open music curriculum, one expanded from mainly Chinese classical or traditional music to include local Chinese music, as well as popular and other types of music from different cultures. These preferences can be seen as a result of the students' increased exposure to different musical styles, both from within China and from other cultures in the world. In addition, the study reveals a continued intra-cultural dichotomy between popular and classical music from different periods within a given culture, an increased inter-cultural dilemma between Chinese popular music and popular music from English-speaking countries, 
and the coexistence of facilitating conditions for and barriers to the promotion of popular music in school.

This study supplements the extant literature by interpreting music and music education as dynamic cultural constructions to explain the diversity and dilemmas of students' learning of popular music in formal and informal music education environments in Shanghai. In a multileveled, multicultural world, different actors, ranging from the global (e.g., global consumer culture and multinational music industry) to the local (e.g., schools, students and individuals), can choose and develop their own combinations of musical styles from different cultures and different levels. Their choices and cultural constructions can be shaped by their immediate and wider contexts, and by their complex interplay with other actors at home or abroad. The study's proposed interpretation has two important theoretical implications for understanding and explaining the complexity of issues surrounding students' learning of popular and classical music in and outside of school.

The first theoretical implication concerns the general division of labor in promoting popular and classical music in and outside of schools in a multileveled cultural world. For students, to a large extent, the two worlds in which they learn popular music, as this study has shown, are disjointed; popular music is not eagerly promoted in the formal musical education environment of the school, but rigorously promoted and widely disseminated by the music industry in the informal musical education environment of the mass media, Internet and related agencies and technologies. Students face a similar, but reversed, dichotomy when learning classical music, which has been given canonical status, both in the history of music and in the school curriculum, and it is sustained mainly in schools and music conservatories. Unlike popular music, however, classical music is largely promoted by the classical music industry and associated agencies (such as orchestras) to a limited audience in an informal music education setting that is characterized by a quiet performance and consumption environment, and that is not amenable to the more boisterous ways in which many young people show their appreciation during popular music performances, such as shouting, cheering, singing along with the artists, and moving their bodies.

These mismatches in promoting and learning popular and classical music, as this study suggests, can be seen as different results of the dynamic and complex interactions between various players who act according to their own needs and conditions in response to changes in the multileveled, multicultural world at various times. Despite these mismatches, students, as autonomous learners in and outside of school, can choose what and to what extent they learn in formal and informal music educational environments, and help to bridge these two worlds of music learning. Like their peers in many other countries, students in Shanghai, as shown in this study, are torn between these two worlds when learning popular or classical music. Although they wanted more opportunities to be exposed to and learn popular music their schools, the students acknowledged the need to keep classical music in the music curriculum, so as to balance their learning with both music styles.

The second theoretical implication of the proposed interpretation relates to the need to open up school music education to narrow the gap in students' music learning. As has been shown throughout human history, music is not static, but dynamic, and music education should be as well. Music differs across time and across cultures. Despite different styles and expressions, classical music and popular music are both integral parts of the broad music tradition, and express people's responses to personal desires and societal needs in different contexts and at different stages in the history of human civilization. As such, music education should not be monopolized by a few dominant musical styles, despite their long history and canonical status. Rather, it should be open and inclusive, promoting both classical and popular music, as well as national/local and world music. As occurred elsewhere, however, the inclusion of popular music in music education in Shanghai encountered both facilitating 
conditions and barriers. Students wanted to learn popular music in school, but doubted their music teachers' ability to teach it. Teachers and school authorities recognized the value of including popular music in music lessons, but saw the government as a major barrier to doing so. All this suggests that, in countries like China, the inclusion of popular music (and other musical styles) in the school music curriculum requires the concerted efforts of all musiceducation stakeholders (including students, music teachers and their trainers, curriculum developers, the music industry and, in particular, the government) to balance the selection, teaching and learning of different music elements from a diversified, multileveled cultural world. 


\section{References}

Brown, V. (2006). Guiding the Influence of Hip-Hop Music on Middle-School Students' Feelings, Thinking, and Behaving. The Negro Educational Review, 57(1-2), 49-68.

Chen, S.-W. (2005). The Rise and Generic Features of Shanghai Popular Songs in the 1930s and 1940s. Popular Music, 24(1), 107-125.

China Internet Network Information Center. (2012). Di 29 Ci Zhongguo Hulian Wangluo Fazhan Zhuangkuang Tongji Baogao [29th Statistical Report on Internet

Development in China]. Beijing: China Internet Network Information Center.

Cohen, L., Manion, L., \& Morrison, K. (2007). Research Methods in Education (6th ed.). London: RoutledgeFalmer.

Communist Party of China Central Committee, \& State Council. (2012, 16 February). Guojia Shierwu Shiqi Wenhua Gaige Fazhan Guihua Gangyao [Outline of China's Cultural Reform and Development in the 12th Five-Year Plan Period (2011-15)]. Renmin Ribao [People's Daily], p. 5.

Dunbar-Hall, P. (2002). Book Review: How Popular Musicians Learn: A Way Ahead for Music Education. Research Studies in Music Education, 18, 79-82.

Dunbar-Hall, P., \& Wemyss, K. (2000). The Effects of the Study of Popular Music on Music Education. International Journal of Music Education, 36, 23-34.

Farrer, J. (2000). Dancing through the Market Transition: Disco and Dance Hall Sociality in Shanghai. In D. S. Davis (Ed.), The Consumer Revolution in Urban China (pp. 226249). Berkeley: University of California Press.

Fung, A. Y. H. (2009). Fandom, Youth and Consumption in China. European Journal of Cultural Studies, 12(3), 285-303.

Green, L. (2001). How Popular Musicians Learn: A Way Ahead for Music Education. Aldershot, UK: Ashgate Publishing Ltd.

Green, L. (2002). From the Western Classics to the World: Secondary Music Teachers' Changing Attitudes in England, 1982 and 1998. British Journal of Music Education, 19(1), 5-30.

Green, L. (2006). Popular Music Education in and for Itself, and for 'Other' Music: Current Research in the Classroom. International Journal of Music Education, 24(2), 101118.

Hallam, S., Rogers, L., \& Creech, A. (2008). Gender Differences in Musical Instrument Choice. International Journal of Music Education, 26(1), 7-19.

Hayhoe, R. (1988). Shanghai as a Mediator of the Educational Open Door. Pacific Affairs, 61(2), 253-284.

Hebert, D. G., \& Campbell, P. S. (2000). Rock Music in American Schools: Positions and Practices since the 1960s. International Journal of Music Education, 36(1), 14-22.

Ho, W.-C. (2002). Musical Behavior of Young Hong Kong Students. Educational Research Journal, 17(2), 197-217.

Ho, W.-C. (2010). Moral Education in China's Music Education: Development and Challenges. International Journal of Music Education, 28(1), 71-87.

Hu, J. T. (2012, 1 January). Jianding Buyi Zou Zhongguo Tese Shehui Zhuyi Wenhua Fazhan Daolu Nuli Jianshe Shehui Zhuyi Wenhua Qiangguo [To Persist in the Road of Developing Socialist Culture with Chinese Characteristics and Work Hard for Building a Strong Nation of Socialist Culture]. Qiushi [Seeking Truth] Retrieved 5 January, 2012, from http://www.qstheory.cn/zxdk/2012/201201/201112/t20111228_132538.htm 
Jaffurs, S. E. (2006). The Intersection of Informal and Formal Music Learning Practices. International Journal of Community Music Retrieved 25 December, 2011, from http://www.intljcm.com/articles/Volume\%204/Jaffurs\%20Files/Jaffurs.pdf

Koizumi, K. (2002). Popular Music, Gender and High School Pupils in Japan: Personal Music in School and Leisure Sites. Popular Music, 21(1), 107-125.

Landsbeger, S. R. (2009). Harmony, Olympic Manners and Morals-Chinese Television and the 'New Propaganda' of Public Service Advertising. European Journal of East Asian Studies, 8(2), 331-355.

Law, W.-W. (2011). Citizenship and Citizenship Education in a Global Age: Politics, Policies, and Practices in China. New York: Peter Lang Publishing.

Mark, M. L., \& Madura, P. (2010). Music Education in Your Hands: An Introduction for Future Teachers. New York: Routledge.

Meizel, K. (2006). A Singing Citizenry: Popular Music and Civil Religion in America. Journal for the Scientific Study of Religion, 45(4), 497-503.

Merriam, S. B. (1998). Qualitative Research and Case Study Applications in Education. San Francisco, CA: Jossey-Bass Publishers.

Mills, S. W. (2000). Recognizing Middle School Students' Taste for Popular Music. General Music Today, 13(3), 3-6.

Ministry of Education. (2001). Yinyue Kecheng Biaozhun [Curriculum Standards for Primary Education and Junior Secondary Education: Music]. Beijing: Beijing Normal University Press.

Ministry of Education. (2011). Yiwu Jiaoyu Yinyue Kecheng Biaozhun [Curriculum Standards for Primary Education and Junior Secondary Education: Music]. Beijing: Beijing Normal University Press.

Patton, M. Q. (1990). Qualitative Evaluation and Research Methods. Newbury Park, CA: Sage.

Pease, R. (2006). Internet, Fadom, and K-Wave in China. In K. Howard (Ed.), Korean Pop Music (pp. 176-189). Folkstone, Kent: Global Oriental.

Seifried, S. (2006). Exploring the Outcomes of Rock and Popular Music Instruction in High School Guitar Class: A Case Study. International Society for Music Education, 24(2), 168-177.

Shah, S. M. (2006). Popular Music in Malaysia: Education from the Outside. International Journal of Music Education, 24(2), 132-139.

Shanghai Juvenile and Children's Publishing House. (2004). Yinyue [Music for Grade 7 , First Term] (4th ed.). Shanghai: Juvenile and Children's Publishing House.

Shanghai Juvenile and Children's Publishing House. (2009). Yinyue [Music for Grade 7, Second Term] (3rd ed.). Shanghai: Juvenile and Children's Publishing House.

Shanghai Juvenile and Children's Publishing House. (2011). Yinyue [Music for Grade 6, First Term] (6th ed.). Shanghai: Juvenile and Children's Publishing House.

Shanghai Municipal Education Commission. (2004). Shanghai Shi Zhongxiaoxue Yinyue Kecheng Biaozhun [Curriculum Standard for Music in Primary and Secondary Schools]. Shanghai: Shanghai Education Press.

Shanghai Municipal Statistical Bureau. (2010). Shanghai Tongji Nianjian 2010 [Shanghai Statistical Yearbook 2010]. Beijing: China Statistics Press.

Shanghai Music Publisher. (2005). Yishu [Arts for Grade 12, Second Term]. Shanghai: Shanghai Music Publisher.

Shin, H. (2009). Have You Ever Seen the Rain? And Who'll Stop the Rain?: The Globalizing Project of Korean Pop (K-pop). Inter-Asia Cultural Studies, 10(4), 507-523. 
Snell, K. (2005). Music Education Through Popular Music Festivals: A study of the OM Music Festival in Ontario, Canada. Action, Criticism \& Theory for Music Education, 4(2), 1-35.

Stuessy, J. (1994). When the Music Teacher Meets Metallica. Music Educators Journal, 79(4), 28-32.

Swanwick, K. (1968). Popular Music and the Teacher. Oxford: Pergamon Press.

Tagg, P. (1966). Pop Music as a Possible Medium in Secondary Education. University of Manchester, Manchester.

Thompson, J. D. (2007). American Idol and the Music Classroom: A Means of Critiquing Music. Music Educators Journal, 94(1), 36-40.

Vulliamy, G., \& Lee, E. (Eds.). (1980). Pop Music in School (rev. ed.). Cambridge: Cambridge University Press.

Walker, R. (2001). The Rise and Fall of Philosophies of Music Education: Looking Backwards in order to See Ahead. Research Studies in Music Education, 17, 3-18.

White, C., \& McCormack, S. (2006). The Message in the Music: Popular Culture and Teaching in Social Studies. The Social Studies, May/June, 122-127.

Wiersma, W., \& Jurs, S. G. (2004). Research Methods in Education: An Introduction (8th ed.). Needham Heights, MA: Allyn \& Bacon.

Winter, N. (2004). The Learning of Popular Music: A Pedagogical Model for Music Educators. International Journal of Music Education, 22(3), 237-247.

Woody, R. H. (2007). Popular Music in School: Remixing the Issues. Music Educators Journal, 93(4), 32-37. 